\title{
SEC11A Expression Is Associated with Basal-Like Bladder Cancer and Predicts Patient Survival
}

\author{
Yoshinori Shigematsu $^{a, b} \quad$ Naohide Oue $^{a}$ Yohei Sekino $^{a, b}$ Naoya Sakamoto ${ }^{a}$ \\ Kazuhiro Sentani ${ }^{a}$ Naohiro Uraoka ${ }^{c}$ Tetsutaro Hayashi ${ }^{b}$ Jun Teishima ${ }^{b}$ \\ Akio Matsubarab ${ }^{b}$ Wataru Yasui ${ }^{a}$ \\ ${ }^{a}$ Department of Molecular Pathology, Hiroshima University Institute of Biomedical and Health Sciences, Hiroshima, \\ Japan; ${ }^{b}$ Department of Urology, Hiroshima University Institute of Biomedical and Health Sciences, Hiroshima, Japan; \\ 'Department of Pathology, Memorial Sloan Kettering Cancer Center, New York, NY, USA
}

\section{Keywords}

SEC11A · EGFR · Bladder cancer · Basal-like bladder cancer

\begin{abstract}
Objectives: Bladder cancer $(\mathrm{BC})$ is a common malignancy worldwide. Signal peptidase complex 18 (SPC18) protein, which is encoded by the SEC11A gene, is one of the subunits of the signal peptidase complex and induces transforming growth factor-a secretion. In the present study, we analyzed the expression and function of SPC18 protein in human BC. Methods: Expression of SPC18 was analyzed by immunohistochemistry. RNA interference was used to inhibit SEC11A expression in $B C$ cell lines. For constitutive expression of the SEC11A gene, a SEC11A expression vector was transfected into $B C$ cell lines. To examine cell viability, we performed 3-(4,5-dimethylthiazol-2-yl)-2,5-diphenyltetrazolium bromide (MTT) assays. Modified Boyden chamber assays were used to examine cell invasiveness. Results: SPC18 was upregulated in $54 \%$ of $81 \mathrm{BC}$ cases. SPC 18 expression served as an independent prognostic classifier of patients with $B C$. SPC18-positive BC cases frequently expressed cytokeratin $5 / 6$, a marker of basal-like BC. Cell growth and invasiveness
\end{abstract}

\section{KARGER}

(c) 2019 S. Karger AG, Basel

E-Mail karger@karger.com

www.karger.com/pat were inhibited by SEC11A knockdown and enhanced by forced expression of SEC11A. Conclusion: These results indicate that SPC18 plays an important role in the progression of BC. Specific inhibitors of SPC18 may be promising anticancer drugs for patients with basal-like BC.

(c) 2019 S. Karger AG, Basel

\section{Introduction}

Bladder cancers (BCs), the majority of which are urothelial carcinomas, are a common malignancy worldwide. The prognosis of patients with $\mathrm{BC}$ is poor when the disease includes muscle invasion. Metastatic BC is usually fatal. However, progress in systemic therapies for muscle-invasive $\mathrm{BC}$ has been stagnant for decades with few new systemic therapies being evaluated until recently [1]. Thus, there is an urgent need for new potential therapeutic targets in $\mathrm{BC}$.

Transforming growth factor (TGF)- $\alpha$ is a mitogenic polypeptide that has a wide range of biological activities [2]. TGF- $\alpha$ phosphorylates the epidermal growth factor receptor (EGFR) and stimulates multiple signaling path-

Naohide Oue

Hiroshima University Institute of Biomedical and Health Sciences

1-2-3 Kasumi, Minami-ku

Hiroshima 734-8551 (Japan)

E-Mail naoue@ hiroshima-u.ac.jp 
ways involved in cell proliferation, anti-apoptosis, and other processes [3]. Overexpression of TGF- $\alpha$ has been reported in BC [3]. However, the detailed mechanisms have not been analyzed. Previously, we reported that signal peptidase complex 18 (SPC18) induces TGF- $\alpha$ secretion in gastric cancer [4]. SPC18 protein, which is encoded by the SEC11A gene, is one of the subunits of the signal peptidase complex. Most secretory proteins contain amino terminal or internal signal peptides that direct their sorting to the endoplasmic reticulum (ER) [5]. From the ER, proteins are transported to either the extracellular space or plasma membrane. The ER signal peptides are then cleaved by the signal peptidase complex. It has been reported that the signal peptidase complex purified from canine microsomes has 5 distinct subunits [6]. Two of these subunits, SPC18 and SPC21, are presumed to have catalytic activity [7]. Therefore, TGF- $\alpha$ secretion can be decreased by SPC18 inhibition. However, expression of SPC18 has not been examined in BC.

TGF- $\alpha$ phosphorylates the EGFR. It has been reported that basal-like BC exhibits activation of the EGFR pathway linked to frequent EGFR overexpression and activation of an EGFR autocrine loop [8]. Furthermore, the prognosis of patients with basal-like $\mathrm{BC}$ has been reported to be poor [8]. Because SPC18 induces TGF- $a$ secretion [4], SPC18 expression may be frequent in basal-like BC. However, SPC18 expression has not been examined in basal-like BC.

In the present study, we analyzed the expression and distribution of SPC18 protein in human BC by immunohistochemistry and examined the relationship between SPC18 protein expression and clinicopathologic characteristics. Furthermore, the association between SPC1 8 expression and basal-like BC was analyzed by immunostaining of cytokeratin 5/6 (CK5/6), a basal-type marker [9]. We also analyzed the effect of inhibiting SPC18 expression by RNA interference (RNAi) on cell growth and invasiveness.

\section{Materials and Methods}

\section{Tissue Samples}

Using a retrospective study design, 89 primary tumors were collected from patients diagnosed with BC, who underwent surgery between 2003 and 2011 at the Hiroshima University Hospital (Hiroshima, Japan). All patients had undergone curative resection. Only patients without preoperative radiotherapy or chemotherapy were enrolled in the study. Operative mortality was defined as death within 30 days of patient discharge. These patients were excluded from the analysis. Postoperative follow-up was scheduled every 1,2 , or 3 months during the first 2 years after surgery and every 6 months thereafter unless more frequent follow-ups were necessary. Chest X-ray, chest computed tomography, and serum chemistries were performed at each follow-up visit. Patients were followed by their physician until death or the date of the last documented contact. Tumor staging was performed according to the TNM (tumor-node-metastasis) classification system [10].

For quantitative reverse transcription polymerase chain reaction (qRT-PCR), we used 8 urothelial carcinoma (UC) samples. The samples were frozen immediately in liquid nitrogen and stored at $-80^{\circ} \mathrm{C}$ until use.

For immunohistochemical analysis, we used archival formalinfixed, paraffin-embedded tissues from 81 patients who had undergone surgical excision for UC. All 81 patients with UC were treated by cystectomy.

\section{qRT-PCR Analysis}

Total RNA was extracted with an RNeasy mini kit (Qiagen, Valencia, CA, USA), and $1 \mu \mathrm{g}$ total RNA was converted to cDNA using a first-strand cDNA synthesis kit (Amersham Biosciences, Piscataway, NJ, USA). Quantitation of SEC11A mRNA levels was performed by real-time fluorescence detection as described previously [11]. PCR was conducted using a SYBR green PCR core reagents kit (Applied Biosystems, Thermo Fisher Scientific, Inc., Waltham, MA, USA). Real-time detection of the emission intensity of SYBR green bound to double-stranded DNA was performed with an ABI PRISM 7700 sequence detection system (Applied Biosystems). ACTB-specific PCR products were amplified from the same RNA samples and served as an internal control.

\section{Immunohistochemistry}

Immunohistochemical analysis was performed with a Dako Envision+ rabbit or mouse peroxidase detection system (Dako Cytomation, Carpinteria, CA, USA). Antigen retrieval was performed by microwave heating in citrate buffer ( $\mathrm{pH}$ 6.0) for $30 \mathrm{~min}$. Peroxidase activity was blocked in sections by incubation with $3 \%$ $\mathrm{H}_{2} \mathrm{O}_{2}$ in methanol for $10 \mathrm{~min}$, followed by incubation with normal goat serum (Dako Cytomation) for $20 \mathrm{~min}$ to block nonspecific antibody binding sites. Sections were incubated with an antiSPC18 antibody [4], anti-CK5/6 antibody (1:50; Dako Cytomation), or anti-EGFR antibody (1:20; Novocastra, Newcastle, UK) for $1 \mathrm{~h}$ at room temperature, followed by incubation with Envision+ anti-rabbit or anti-mouse peroxidase for $1 \mathrm{~h}$. For color development, sections were incubated with DAB substrate-chromogen solution (Dako Cytomation) for $10 \mathrm{~min}$. Sections were counterstained with $0.1 \%$ hematoxylin. Negative controls were prepared by omission of the primary antibody.

Expression of SPC18, CK5/6, and EGFR was scored in all tumors as positive or negative. When $>10 \%$ of tumor cells were stained, the immunostaining was considered as positive. Using this definition, 2 surgical pathologists (N.O. and K.S.) without knowledge of the clinical and pathological parameters or the patient outcomes independently reviewed the immunoreactivity in each specimen. Interobserver differences were resolved by consensus review under a double-headed microscope after independent review.

\section{Cell Lines}

We used 2 cell lines derived from human BC (T24 and KMBC$2)$. Both cell lines were purchased from the Japanese Collection of Research Bioresources Cell Bank (Osaka, Japan). The cell lines were maintained in RPMI 1640 (Nissui Pharmaceutical Co, Ltd, 
Tokyo, Japan) containing 10\% fetal bovine serum (BioWhittaker, Walkersville, MD, USA) at $37^{\circ} \mathrm{C}$ in a humidified atmosphere with $5 \% \mathrm{CO}_{2}$.

\section{Western Blot Analysis}

Cells were lysed as described previously [12]. The lysates (40 $\mu \mathrm{g}$ protein) were solubilized in Laemmli sample buffer by boiling and then subjected to $10 \%$ sodium dodecyl sulfate polyacrylamide gel electrophoresis followed by electrotransfer onto a nitrocellulose filter. Western blot procedures were performed as described previously [12]. An anti-SPC18 antibody was prepared as described previously [4]. Anti-EGFR, anti-phosphorylated EGFR, anti-ERK1/2, anti-phosphorylated ERK1/2, anti-AKT, and anti-phosphorylated AKT antibodies were purchased from Cell Signaling Technology (Danvers, MA, USA). Peroxidase-conjugated anti-rabbit IgG or anti-mouse IgG were used in the secondary reaction. Immunocomplexes were visualized with an ECL Western blot detection system (Amersham Biosciences).

\section{RNAi, Expression Vector, and Transfection}

Short interfering RNA (siRNA) oligonucleotides targeting SE$C 11 A$ and a negative control were purchased from Invitrogen (Carlsbad, CA, USA). We used 2 independent SEC11A siRNA oligonucleotide sequences. Transfection was performed using Lipofectamine RNAiMAX (Invitrogen) as described previously [13]. Briefly, 60 pmol siRNA and $10 \mu \mathrm{L}$ Lipofectamine RNAiMAX were mixed in $1 \mathrm{~mL}$ RPMI 1640 medium $(10 \mathrm{nmol} / \mathrm{L}$ final concentration). After $20 \mathrm{~min}$ of incubation, the mixture was added to the cells, and then the cells were plated in culture dishes. At $48 \mathrm{~h}$ after transfection, the cells were analyzed.

For constitutive expression of the SEC11A gene, cDNA was PCR amplified and subcloned into pcDNA 3.1 (Life Technologies, Carlsbad, CA, USA). The SEC11A expression vector was transfected into T24 and KMBC-2 cells with FuGENE6 (Roche Diagnostics, Indianapolis, IN, USA), according to the manufacturer's instructions. Stable transfectants were selected after 2 weeks of culture with $100 \mu \mathrm{g} / \mathrm{mL}$ G418 (Life Technologies).

\section{Cell Growth and Invasion Assays}

Cell growth was monitored after 1, 2, and 4 days by the 3-(4,5-dimethylthiazol-2-yl)-2,5-diphenyltetrazolium bromide (MTT) assay as described previously [14]. Three independent experiments were carried out. The mean \pm standard error (SE) was calculated for each experiment.

A modified Boyden chamber assay was performed to examine cell invasiveness. Cells were plated at 10,000 cells per well in RPMI 1640 medium plus $1 \%$ serum in the upper chamber of a Transwell insert ( 8 - $\mu \mathrm{m}$ pore diameter; Chemicon, Temecula, CA, USA) coated with Matrigel. Medium containing $10 \%$ serum was added to the bottom chamber. After 2 days, cells in the upper chamber were removed by scraping, and cells on the lower surface of the insert were stained with CyQuant GR dye to assess the number of cells. Three independent experiments were carried out. The mean \pm SE was calculated for each experiment.

\section{Statistical Methods}

Associations between clinicopathological parameters and SPC18 expression were analyzed by Fisher's exact test. KaplanMeier survival curves were constructed for SPC18-positive and -negative patients. Differences between survival curves were tested for statistical significance by the log-rank test. Univariate and multivariate Cox regressions were used to evaluate the associations between clinical covariates and cancer-specific mortality. The hazard ratio and 95\% confidence interval were estimated from Cox proportional hazard models. A $p$ value $<0.05$ was considered to be statistically significant. Differences between the two groups (SEC11A siRNA- and negative control siRNA-transfected cells) were tested by the Student $t$ test.

\section{Results}

\section{Expression of SEC11A in BC}

We first analyzed SEC11A mRNA expression in $8 \mathrm{BC}$ tissue samples and a nonneoplastic mucosa sample by qRT-PCR (Fig. 1a) and observed overexpression of SEC11A (tumor/nonneoplastic mucosa ratio $>2$ ) in 6 (75\%) of the $8 \mathrm{BC}$ tissue samples.

Next, immunohistochemistry of SPC18 was performed in 81 BC tissue samples. In nonneoplastic mucosa, weak or no staining of SPC18 was observed in the epithelial and stromal cells. In contrast, BC tissue showed stronger, more extensive staining (Fig. 1b). SPC18 was detected in the cytoplasm of tumor cells (Fig. 1c). Many BC cases showed heterogeneity of SPC18 staining, and the percentage of SPC18-stained BC cells ranged from 0 to $80 \%$. A tendency for upregulation of SPC18 was not observed at the invasive front. We next examined the relationship of SPC18 expression with clinicopathological characteristics (Table 1). When at least $10 \%$ of tumor cells were stained, the immunostaining was considered positive for SPC18. In total, 44 (54\%) of 81 BC cases were positive for SPC18. Expression of SPC18 was associated with vascular invasion, histological grade, histological, $\mathrm{T}$, and $\mathrm{N}$ classification, and tumor stage. We found that SPC18 expression was significantly associated with overall survival $(p=0.003$, log-rank test; Fig. 1d). Univariate analysis indicated that lymphatic invasion, vascular invasion, $\mathrm{T}, \mathrm{N}$, and $\mathrm{M}$ classification, tumor stage, and SPC18 expression were associated with overall survival. In the multivariate model, tumor stage and SPC18 expression were independent predictors of BC patient survival. These results suggest that SPC18 is a promising biomarker to identify patients with a poor prognosis.

\section{SPC18 Expression in Basal-Like BC}

To analyze the association between SPC18 expression and basal-like BC, immunostaining of CK5/6 was performed in $81 \mathrm{BC}$ tissue samples. When at least $10 \%$ of tumor cells were stained, the immunostaining was considered positive for CK5/6. In total, 39 (48\%) of $81 \mathrm{BC}$ cases were positive for CK5/6. Expression of CK5/6 was 
not associated with any clinicopathological characteristics. Furthermore, CK5/6 expression was not associated with overall survival (data not shown). In contrast, SPC18 staining was observed in CK5/6-positive BC cells (Fig. 2). SPC18-positive BC cases had a significantly increased frequency of CK5/6 positivity $(p<0.0001$; Table 2$)$.

Table 1. Relationship between SPC18 expression and clinicopathological characteristics of bladder cancer

\begin{tabular}{|c|c|c|c|}
\hline & \multicolumn{3}{|c|}{ SPC18 expression } \\
\hline & positive & negative & $p\left(\chi^{2}\right.$ test $)$ \\
\hline \multicolumn{4}{|l|}{ Age } \\
\hline$<65$ years & $12(43 \%)$ & 16 & \multirow[t]{2}{*}{0.132} \\
\hline$\geq 65$ years & $32(60 \%)$ & 21 & \\
\hline \multicolumn{4}{|l|}{ Sex } \\
\hline Male & $36(54 \%)$ & 31 & \multirow[t]{2}{*}{0.815} \\
\hline Female & $8(57 \%)$ & 6 & \\
\hline \multicolumn{4}{|c|}{ Lymphatic invasion } \\
\hline Positive & $22(58 \%)$ & 16 & \multirow[t]{2}{*}{0.5436} \\
\hline Negative & $22(51 \%)$ & 21 & \\
\hline \multicolumn{4}{|l|}{ Vascular invasion } \\
\hline Positive & $15(79 \%)$ & 4 & \multirow[t]{2}{*}{0.0112} \\
\hline Negative & $29(47 \%)$ & 33 & \\
\hline \multicolumn{4}{|c|}{ Histological grade } \\
\hline $\mathrm{G} 1 / \mathrm{G} 2$ & $6(33 \%)$ & 12 & \multirow[t]{2}{*}{0.0420} \\
\hline G3 & $38(60 \%)$ & 25 & \\
\hline \multicolumn{4}{|c|}{ Histological classification } \\
\hline Pure UC & $36(50 \%)$ & 36 & \multirow[t]{2}{*}{0.0180} \\
\hline $\mathrm{UC} / \mathrm{SD}$ & $8(89 \%)$ & 1 & \\
\hline \multicolumn{4}{|l|}{$\mathrm{T}$ classification } \\
\hline $\mathrm{Ta} / \mathrm{is} / 1$ & $12(32 \%)$ & 25 & \multirow[t]{2}{*}{0.0002} \\
\hline $\mathrm{T} 2 / 3 / 4$ & $32(73 \%)$ & 12 & \\
\hline \multicolumn{4}{|l|}{$\mathrm{N}$ classification } \\
\hline No & $33(48 \%)$ & 36 & \multirow[t]{2}{*}{0.0023} \\
\hline N1 & $11(92 \%)$ & 1 & \\
\hline \multicolumn{4}{|l|}{ M classification } \\
\hline M0 & $41(53 \%)$ & 37 & \multirow[t]{2}{*}{0.0525} \\
\hline M1 & $3(100 \%)$ & 0 & \\
\hline \multicolumn{4}{|l|}{ Stage } \\
\hline Stage $0 / \mathrm{I} / \mathrm{II}$ & $22(44 \%)$ & 28 & \multirow[t]{2}{*}{0.0166} \\
\hline Stage III/IV & $22(71 \%)$ & 9 & \\
\hline
\end{tabular}

Fig. 1. Expression of SEC11A in BC. a qRT-PCR analysis of SEC11A mRNA in normal bladder and 8 bladder cancer (BC) tissue samples. b Immunostaining of SPC18 in nonneoplastic mucosa and BC. Original magnification, $\times 40$. c High magnification image of the field indicated by the box in $\mathbf{b}$. Original magnification, $\times 400$. d Kaplan-Meier plot of BC patient survival according to SPC18 expression.

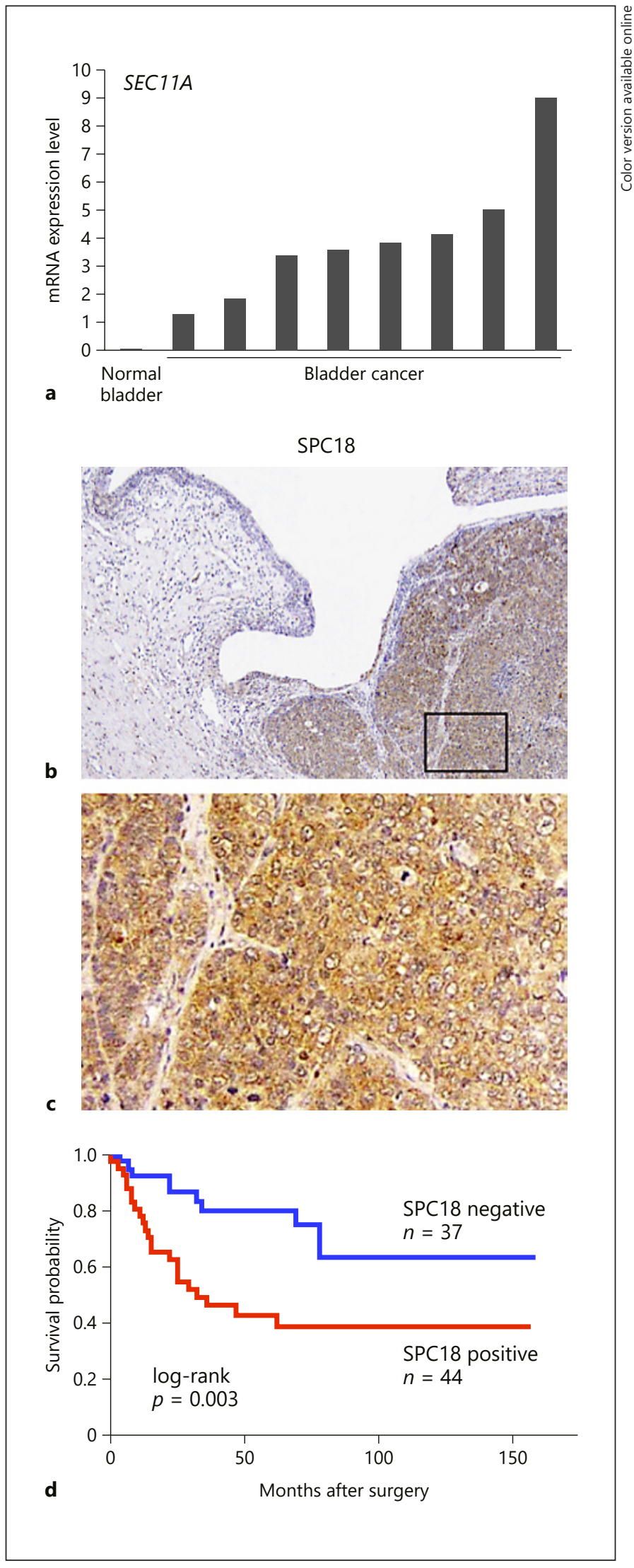

Pathobiology 2019;86:208-216 

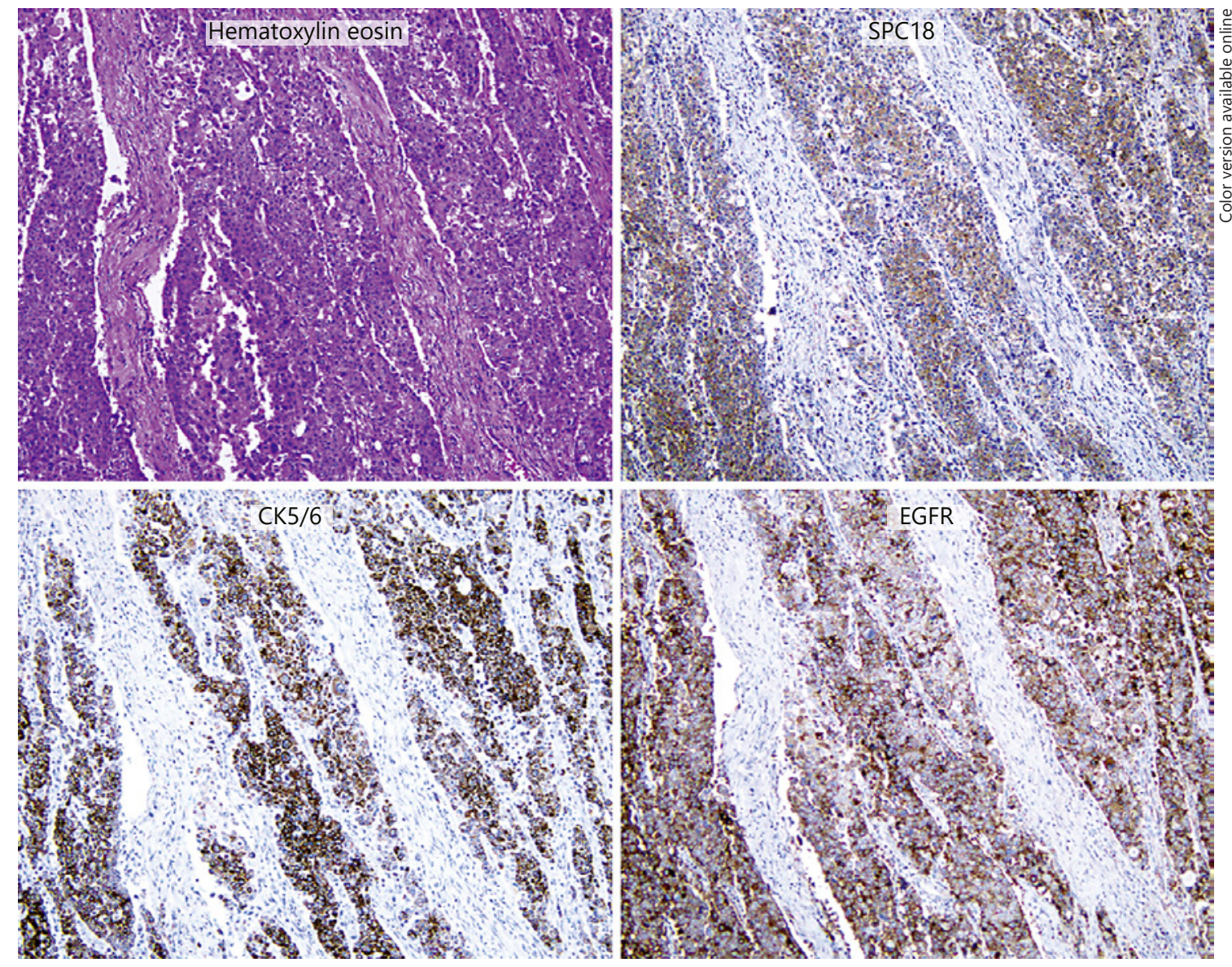

Fig. 2. Immunostaining of SPC18, cytokeratin 5/6 (CK5/6), and epidermal growth factor receptor (EGFR). Original magnification, $\times 100$.

Next, we analyzed EGFR expression by immunohistochemistry and confirmed that all SPC18-positive BC cases were positive for EGFR (Fig. 2). These results indicate that the EGFR pathway could be activated in SPC18-positive $\mathrm{BC}$ cases.

Effect of SEC11A Inhibition or Overexpression on Cell Growth and Invasion

Previously, we showed that inhibition of SEC11A by siRNA reduces cell growth, and the levels of phosphorylated EGFR and AKT are lower in SEC11A siRNA-transfected gastric cancer cells than in control cells [4]. However, the biological function of SEC11A has not been investigated in $\mathrm{BC}$ cells. Therefore, we examined the effect of SEC11A inhibition on cell growth using 2 different siRNA sequences. T24 BC cells were selected, which expressed detectable levels of SPC18 protein by Western blotting (Fig. 3a). The SPC18 expression in T24 cells was substantially suppressed by treatment with siRNA1 and
siRNA2 as shown by Western blotting (Fig. 3b). Next, cell growth was analyzed by MTT assays. SEC11A siRNA1and siRNA2-transfected T24 cells showed significantly reduced cell growth relative to negative control siRNAtransfected T24 cells (Fig. 3c).

To further investigate the function of SPC18, KMBC-2 cells were stably transfected with pcDNA-SEC11A. Clones were selected in G418 and examined for SPC18 protein expression by Western blotting. Two clones, stable lines 1 and 2, expressed SPC18 at significantly higher levels than KMBC-2 cells transfected with the empty vector (Fig. 3b). To investigate the effect of SPC18 on cell growth, we performed MTT assays. Cell growth was significantly enhanced in pcDNA-SEC11A-transfected cells compared with empty vector-transfected cells (Fig. 3c). These results indicate that SPC18 promotes tumor growth.

In the present study, immunohistochemical analysis demonstrated that expression of SPC18 was associated 
Table 2. Univariate and multivariate Cox regression analyses of SPC18 expression and survival of bladder cancer patients

\begin{tabular}{|c|c|c|c|c|}
\hline \multirow[t]{2}{*}{ Characteristics } & \multicolumn{2}{|l|}{ Univariate analysis } & \multicolumn{2}{|c|}{ Multivariate analysis } \\
\hline & HR (95\% CI) & $p$ value & $\operatorname{HR}(95 \% \mathrm{CI})$ & $p$ value \\
\hline \multicolumn{5}{|l|}{ Age } \\
\hline$\leq 65$ years & 1 (ref.) & & & \\
\hline$>65$ years & $1.58(0.75-3.6)$ & 0.2324 & & \\
\hline \multicolumn{5}{|l|}{ Sex } \\
\hline Male & 1 (ref.) & & & \\
\hline Female & $0.72(0.25-1.73)$ & 0.4930 & & \\
\hline \multicolumn{5}{|c|}{ Lymphatic invasion } \\
\hline Negative & 1 (ref.) & & 1 (ref.) & \\
\hline Positive & $2.79(1.35-6.19)$ & 0.0051 & $2.40(0.89-6.74)$ & 0.0823 \\
\hline \multicolumn{5}{|c|}{ Vascular invasion } \\
\hline Negative & 1 (ref.) & & 1 (ref.) & \\
\hline Positive & $2.38(1.12-4.84)$ & 0.0247 & $0.93(0.38-2.24)$ & 0.8896 \\
\hline \multicolumn{5}{|l|}{ Grade } \\
\hline G1/G2 & 1 (ref.) & & & \\
\hline G3 & $2.20(0.86-7.44)$ & 0.1052 & & \\
\hline \multicolumn{5}{|c|}{ Histological subtype } \\
\hline Pure UC & 1 (ref.) & & & \\
\hline UC/SD & $2.29(0.91-5.03)$ & 0.0757 & & \\
\hline \multicolumn{5}{|l|}{$\mathrm{T}$ classification } \\
\hline Ta/Tis/T1 & 1 (ref.) & & 1 (ref.) & \\
\hline T2/T3/T4 & $2.46(1.17-5.61)$ & 0.0163 & $0.48(0.13-1.64)$ & 0.2436 \\
\hline \multicolumn{5}{|l|}{$\mathrm{N}$ classification } \\
\hline No & 1 (ref.) & & 1 (ref.) & \\
\hline N1 & $5.14(2.22-11.32)$ & 0.0003 & $1.36(0.49-3.90)$ & 0.5528 \\
\hline \multicolumn{5}{|l|}{ M classification } \\
\hline M0 & 1 (ref.) & & 1 (ref.) & \\
\hline M1 & $5.25(1.22-15.63)$ & 0.0291 & $1.50(0.31-5.46)$ & 0.5799 \\
\hline \multicolumn{5}{|l|}{ Stage } \\
\hline 0/I/II & 1 (ref.) & & 1 (ref.) & \\
\hline III/IV & $4.17(2.04-8.77)$ & $<0.0001$ & $3.05(1.01-10.00)$ & 0.0476 \\
\hline \multicolumn{5}{|c|}{ SPC18 expression } \\
\hline Negative & 1 (ref.) & & 1 (ref.) & \\
\hline Positive & $3.14(1.47-7.48)$ & 0.0027 & $3.11(1.15-9.34)$ & 0.0250 \\
\hline
\end{tabular}

HR, hazard ratio; CI, confidence interval.

with vascular invasion and the T classification. Thus, we analyzed the possible role of SPC18 in the invasiveness of BC cells. We performed modified Boyden chamber assays using T24 cells. On day 2, the invasiveness of SEC11A siRNA1- and siRNA2-transfected T24 cells was less than that of negative control siRNA-transfected cells (Fig. 3d). We also performed invasion assays using KMBC-2 cells. On day 2, invasiveness was significantly enhanced in pcDNA-SEC11A-transfected cells compared with empty vector-transfected cells (Fig. 3d). These results indicate that SPC18 also enhances invasiveness.

\section{Effect of SEC11A Inhibition or Overexpression on}

\section{EGFR Signaling}

Because EGFR activates RAS-MEK-ERK1/2 and AKTPI3K pathways leading to cancer cell proliferation and survival [15], we analyzed the effect of SEC11A inhibition on EGFR signaling. The levels of phosphorylated EGFR, AKT, and ERK1/2 were lower in SEC11A siRNA1- and siRNA2transfected T24 cells than in negative control siRNA-transfected cells (Fig. 3e). We also analyzed the levels of phosphorylated EGFR, AKT, and ERK1/2 in KMBC-2 cells. The levels of phosphorylated EGFR, AKT, and ERK1/2 were higher in pcDNA-SEC11A-transfected cells compared 




Fig. 3. Effect of SEC11A inhibition or overexpression on BC cell lines. a Western blot analysis of SPC18. MKN-45 is a gastric cancer cell line and served as a positive control. b Western blot analysis of SPC18 in T24 cells transfected with negative control siRNA or SEC11A siRNAs (left panel). Western blot analysis of SPC18 in KMBC-2 cells stably transfected with pcDNA-SEC11A or the empty vector (right panel). c, d Bars and error bars indicate the mean and SE, respectively, of 3 independent experiments. c Cell viability was assessed by MTT assays on days 1,2, and 4 after seeding in 96-well plates. Effect of SEC11A knockdown on T24 cell growth (left panel)and effect of SEC11A overexpression on KMBC-

with empty vector-transfected cells (Fig. 3e). We also analyzed expression of CK5/6 by immunostaining in BC cell lines because SPC18-positive BC cases had a significantly increased frequency of $\mathrm{CK} 5 / 6$ positivity in $\mathrm{BC}$ tissue specimens. However, expression of CK5/6 was not significantly changed in SEC11A siRNA-transfected T24 cells and pcDNA-SEC11A-transfected KMBC-2 cells. These results indicate that SPC18 activates EGFR signaling.

Next, we examined epithelial-mesenchymal transition in BC cell lines because EGFR signaling is involved in epithelial-mesenchymal transition [16]. Expression of CDH1 and VIM was measured by qRT-PCR. However,
2 cell growth (right panel). d Effect of SEC11A knockdown on T24 cell invasiveness (left panel) and effect of SEC11A overexpression on KNBC-2 cell invasiveness (right panel) evaluated by the modified Boyden chamber assay. e Western blot analysis of SPC18, epidermal growth factor receptor (EGFR), phosphorylated EGFR (pEGFR), AKT, and phosphorylated AKT (pAKT), ERK1/2, and phosphorylated ERK1/2 (pERK1/2) in lysates of T24 cells transfected with the negative control siRNA or SEC11A siRNAs (left panel) and in lysates of KMBC-2 cells stably transfected with pcDNA-SEC11A or the empty vector (right panel).

expression of $C D H 1$ and VIM was not significantly changed in SEC11A siRNA-transfected T24 cells and pcDNA-SEC11A-transfected KMBC-2 cells.

\section{Discussion}

Previously, we reported overexpression of SPC18 in gastric and colorectal cancers. SPC18 expression is associated with tumor progression and patient survival in both gastric and colorectal cancers $[4,17]$. In the present study, we analyzed the expression and distribution of SPC18 pro- 
tein in human BC by immunostaining. In nonneoplastic mucosa, weak or no staining of SPC18 was observed in epithelial and stromal cells, whereas BC tissue showed stronger, more extensive staining. We found that SPC18 was upregulated in 54\% of 81 BC cases. SPC18 expression was associated with vascular invasion, histological grade, histological classification, $\mathrm{T}$ and $\mathrm{N}$ classification, and tumor stage. These results indicate that SPC18 plays a major role in the progression of BC. Furthermore, SPC18 expression was correlated with overall survival and served as an independent prognostic classifier of patients with BC. These results suggest that SPC18 immunostaining is a clinically useful method to predict BC patient survival.

SPC18 protein is one of the subunits of the signal peptidase complex and has catalytic activity of signal peptidase [7]. Increased activity of the signal peptidase complex caused by SPC18 protein overexpression may induce secretion of several kinds of growth factors. In fact, we have reported that SPC18 induces TGF- $\alpha$ secretion in gastric cancer [4]. In the present study, we showed that cell growth was inhibited by SEC11A knockdown and enhanced by forced expression of SEC11A, suggesting that secretion of several kinds of growth factors, including TGF- $\alpha$, could be activated by SPC18 expression. We confirmed that the levels of phosphorylated EGFR, AKT, and ERK1/2 were reduced by SEC11A knockdown and enhanced by forced expression of SEC11A. These results indicate that SPC18 plays a major role in $\mathrm{BC}$ cell growth.

In the present study, SPC18-positive $\mathrm{BC}$ cases were frequently positive for CK5/6. CK5/6 is a basal-type marker [9], and CK5/6-positive BC is classified as basallike BC. It has been reported that the EGFR pathway is activated in basal-like BC [8]. In our analysis, SPC18 expression induced phosphorylation of EGFR, AKT, and $\mathrm{ERK} 1 / 2$ in BC cell lines, indicating that SPC18 is involved in the activation of the EGFR pathway in basal-like BC. Although clinical trials could not demonstrate the effectiveness of anti-EGFR therapy for BC, blockade of the EGFR pathway may be effective for basal-like BC [18]. In addition to EGFR, SPC18 may be a therapeutic target.

In summary, we found SPC18 overexpression in BC. We also showed that SEC11A knockdown inhibited tumor cell growth and EGFR signaling. Because SPC18 staining was an independent prognostic indicator, immunostaining of SPC18 may be a suitable method to identify patients with a poor prognosis. SPC18-positive $\mathrm{BC}$ cases were frequently found to have basal-like BC. Specific inhibitors of SPC18 may be promising anticancer drugs for patients with basal-like BC.

\section{Acknowledgments}

This work was supported by Grants-in-Aid for Scientific Research (B-15H04713) and for Challenging Exploratory Research (26670175, 16K15247) from the Japan Society for the Promotion of Science and by the Takeda Science Foundation. We thank Sarah Williams, PhD, from Edanz Group (www.edanzediting.com) for editing a draft of this manuscript.

\section{Statement of Ethics}

This study was approved by the Ethics Committee for Human Genome Research of the Hiroshima University (Hiroshima, Japan). Because written informed consent was not obtained, for strict privacy protection, identifying information for all samples was removed before analysis.

\section{Disclosure Statement}

The authors declare no conflict of interest.

\section{References}

1 Knollman H, Godwin JL, Jain R, Wong YN, Plimack ER, Geynisman DM. Muscle-invasive urothelial bladder cancer: an update on systemic therapy. Ther Adv Urol. 2015 Dec; 7(6):312-30.

2 Gangarosa LM, Dempsey PJ, Damstrup L, Barnard JA, Coffey RJ. Transforming growth factor-alpha. Baillieres Clin Gastroenterol. 1996 Mar; 10(1):49-63.

3 Thøgersen VB, Sørensen BS, Poulsen SS, Orntoft TF, Wolf H, Nexo E. A subclass of HER1 ligands are prognostic markers for survival in bladder cancer patients. Cancer Res. 2001 Aug;61(16):6227-33.
4 Oue N, Naito Y, Hayashi T, Takigahira M, Kawano-Nagatsuma A, Sentani K, et al. Signal peptidase complex 18, encoded by SEC11A, contributes to progression via TGF- $\alpha$ secretion in gastric cancer. Oncogene. 2014 Jul; 33(30):3918-26.

5 Nickel W, Rabouille C. Mechanisms of regulated unconventional protein secretion. Nat Rev Mol Cell Biol. 2009 Feb; 10(2):148-55. Erratum in: Nat Rev Mol Cell Biol. 2009 Mar; 10(3):234

6 Greenburg G, Shelness GS, Blobel G. A subunit of mammalian signal peptidase is homologous to yeast SEC11 protein. J Biol Chem. 1989 Sep;264(27):15762-5.
7 Shelness GS, Blobel G. Two subunits of the canine signal peptidase complex are homologous to yeast SEC11 protein. J Biol Chem. 1990 Jun;265(16):9512-9.

8 Rebouissou S, Bernard-Pierrot I, de Reyniès A, Lepage ML, Krucker C, Chapeaublanc E, et al. EGFR as a potential therapeutic target for a subset of muscle-invasive bladder cancers presenting a basal-like phenotype. Sci Transl Med. 2014 Jul;6(244):244ra91.

9 Kobayashi K, Matsumoto H, Matsuyama H, Fujii N, Inoue R, Yamamoto Y, et al. Clinical significance of $\mathrm{CD} 44$ variant 9 expression as a prognostic indicator in bladder cancer. Oncol Rep. 2016 Nov;36(5):2852-60. 
10 Sobin LH, Gospodarowicz MK, Wittekind $\mathrm{CH}$. TMN classification of malignant tumors. 7th ed. New York: Wiley-Liss; 2009. p. 66-72.

11 Kondo T, Oue N, Yoshida K, Mitani Y, Naka $\mathrm{K}$, Nakayama H, et al. Expression of POT1 is associated with tumor stage and telomere length in gastric carcinoma. Cancer Res. 2004 Jan;64(2):523-9.

12 Yasui W, Ayhan A, Kitadai Y, Nishimura K, Yokozaki $\mathrm{H}$, Ito $\mathrm{H}$, et al. Increased expression of p34cdc2 and its kinase activity in human gastric and colonic carcinomas. Int J Cancer. 1993 Jan;53(1):36-41.

13 Sakamoto N, Oue N, Sentani K, Anami K, Uraoka N, Naito Y, et al. Liver-intestine cadherin induction by epidermal growth factor receptor is associated with intestinal differentiation of gastric cancer. Cancer Sci. 2012 Sep; 103(9):1744-50.

14 Alley MC, Scudiero DA, Monks A, Hursey ML, Czerwinski MJ, Fine DL, et al. Feasibility of drug screening with panels of human tumor cell lines using a microculture tetrazolium assay. Cancer Res. 1988 Feb;48(3):589601.

15 Li S, Schmitz KR, Jeffrey PD, Wiltzius JJ, Kussie P, Ferguson KM. Structural basis for inhibition of the epidermal growth factor receptor by cetuximab. Cancer Cell. 2005 Apr; 7(4):301-11.

16 Fustaino V, Presutti D, Colombo T, Cardinali B, Papoff G, Brandi R, et al. Characteriza- tion of epithelial-mesenchymal transition intermediate/hybrid phenotypes associated to resistance to EGFR inhibitors in non-small cell lung cancer cell lines. Oncotarget. 2017 Sep;8(61):103340-63.

17 Hattori T, Sentani K, Naohide O, Sakamoto $\mathrm{N}$, Yasui W. Clinicopathological significance of SPC18 in colorectal cancer: SPC18 participates in tumor progression. Cancer Sci. 2017 Jan;108(1):143-50.

18 Kiselyov A, Bunimovich-Mendrazitsky S, Startsev V. Key signaling pathways in the muscle-invasive bladder carcinoma: clinical markers for disease modeling and optimized treatment. Int J Cancer. 2016 Jun;138(11): 2562-9. 